\title{
Meninas e Jovens na Computação
}

\section{Maria Eduarda Romagna ${ }^{1}$, Letícia Heinzmann², Júlia Marques Carvalho da Silva ${ }^{3}$}

\author{
Instituto Federal de Educação, Ciência e Tecnologia do Rio Grande do Sul - Campus \\ Bento Gonçalves ${ }^{123}$ \\ maria.e.romagna@gmail.com ${ }^{1}$, leticiaheinzmann@gmail.com ${ }^{2}$, \\ julia.silva@bento.ifrs.edu.br ${ }^{3}$
}

\begin{abstract}
Over the years the Information Technology underwent an expansion that is being accompanied by the female audience and the young, although not in the same proportion as others. The project "Meninas e Jovens na Computação (which means, in literal translation, "Women and Teenagers in Information Technology") carries out actions aimed at contributing to include this population in the area of IT, through events to integrate and bring the community into the activities developed. In addition to encouraging the permanence in the course, also contributing to people discover thir interest by IT. The main of these activities was the development of web programming distance education courses and the research "Mulheres na Computação" ("Women in IT").
\end{abstract}

Resumo. Ao longo dos anos a Informática passou por uma expansão exponencial que foi acompanhada pelo público feminino e pelos jovens, mas notavelmente em menor proporção do que pelos outros públicos. O projeto Meninas e Jovens na Computação realiza ações que visam contribuir para aumentar a participação deste público na área de TI por meio de eventos para integrar e abranger a comunidade nas atividades desenvolvidas, além de incentivar a permanência nos cursos, também contribuindo para as pessoas descobrirem seu interesse pela área de TI. A principal dessas ações foi o desenvolvimento de cursos de programação web EAD, com vagas reservadas a mulheres e jovens e a pesquisa "Mulheres na Computação".

\section{Introdução}

A Informática é uma área em grande expansão, segundo o IBGE (2006). Conforme levantamento realizado pela IDC Brasil, a área já apresenta 40 mil vagas disponíveis e a previsão é que o número suba para 117 mil no final de 2015. Diante disso, a desigualdade de gênero se faz ainda mais evidente. Conforme a pesquisa realizada pelo PNAD - IBGE em 2009, 79\% das mulheres que ingressam em cursos acadêmicos de TI não concluem o curso, e apenas $20 \%$ dos profissionais de Tecnologia da Informação no Brasil são mulheres. Ainda, para ampliar o número de mulheres e jovens interessados pela informática, o Ministério da Ciência, Tecnologia e Inovação lançou, em 2013, o Programa Ensino Médio Inovador, onde buscavam incentivar principalmente meninas cursando o ensino médio ou a graduação a inserir-se na área, além de permanecer na mesma. Com base nesses dados, o projeto Meninas e Jovens na Computação tenta entender o porquê das desistências e busca atrair mais mulheres e jovens para a área por 
meio de ações de empoderamento, como o curso de capacitação de programação web EaD e a pesquisa "Mulheres na Computação".

\section{Os cursos}

Para incentivar a aprendizagem da comunidade foi oferecido um curso presencial de informática básica, abrangendo temas como a utilização do computador e seus softwares básicos. Também foram oferecidos cursos de programação web online abertos a toda a comunidade. A plataforma utilizada nos cursos foi o Moodle, ferramenta que oferece um ambiente propício para a realização dos cursos. Cada aula tinha a duração de uma semana, tendo cada semana um assunto. Por exemplo, na primeira semana de PHP viu-se Introdução ao PHP, na segunda estudou-se Operadores e Desvios Condicionais e assim nas conseguintes semanas. Dentre os cursos oferecidos estiveram Lógica de Programação, HTML, CSS, JavaScript e PHP.

O curso de capacitação foi uma das grandes ações realizadas pelo projeto, vindo com a proposta de atingir um número maior de pessoas e auxiliando a disseminar o conhecimento de programação web a um público de nível superior. O mesmo encontra-se finalizado e obteve, num total de soma entre todos os cursos, 77 inscritas mulheres e 139 homens.

Para dar suporte aos alunos matriculados, os bolsistas do projeto Meninas e Jovens na Computação foram escalados como tutores/professores. Dividiram-se para que cada tutor recebe-se, distribuídos de acordo com a sua localização geográfica, um pequeno número de alunos. O tutor era responsável por corrigir os exercícios enviados, monitorar presença do aluno no curso e responder eventuais questionamentos.

O curso de HTML foi o primeiro a ser concluído. Pela grande procura foi ofertado em três versões. Somando seus participantes houve 45 mulheres e 77 homens inscritos sendo que desses apenas 8 mulheres concluíram em contraste aos 18 homens. Em CSS, oferecido duas vezes, o curso obteve 45 mulheres e 77 homens inscritos, assim como em HTML, mas o número de concluintes é ainda menor e mais alarmante: 6 mulheres para 17 homens. Para JavaScript a procura foi mais baixa, totalizando 41 mulheres e 64 homens participando e apenas 1 mulher concluinte para 6 homens. No curso de PHP foram, entre mulheres e homens, respectivamente, 46 e 76 inscritos e 5 e 10 concluintes. Por último, Lógica de Programação obteve, por sua vez, 53 mulheres e 79 homens inscritos. Foi o único dos cursos a ter um número maior de mulheres concluintes: 13 para apenas 9 homens. A alternativa escolhida para combater esse quadro foi destinar 50\% das vagas dos cursos exclusivamente para mulheres e jovens. 


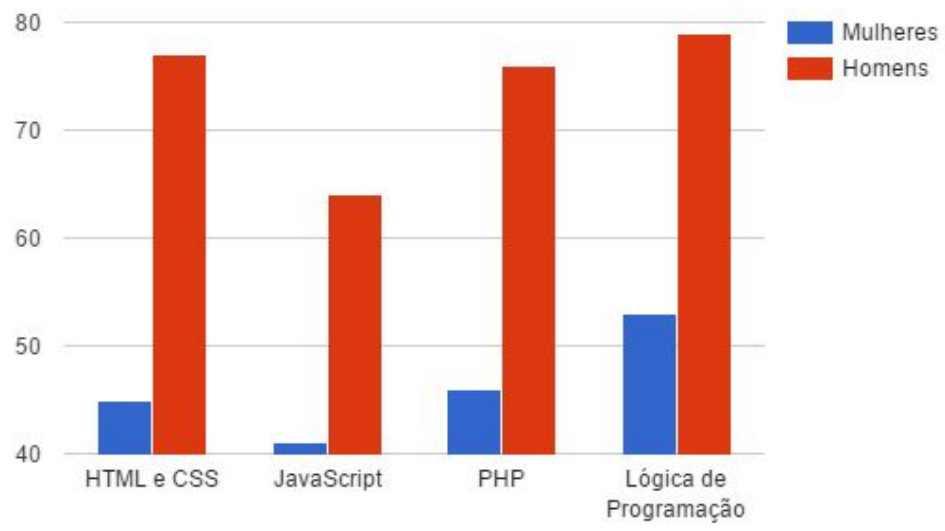

Figura 1. Gráfico comparativo de homens e mulheres nos cursos de programação web EAD.

\section{Pesquisa "Mulheres na Computação"}

A pesquisa foi realizada a fim de descobrir e avaliar a presença da mulher dentro da área de TI atualmente. A pesquisa foi aplicada a alunos dos cursos de Informática para Internet da instituição. O questionário apresentava questões que buscavam entender os motivos para a escolha do curso, interesses em seguir na carreira, entre outras.

Por meio desta pesquisa é possível observar a desigualdade no número de mulheres na área quando comparado ao número de homens. Dentre todas as turmas entrevistadas pôde-se concluir que em média havia somente $20 \%$ de presença feminina nos discentes de informática. Dentre as alunas mulheres do $1^{\circ}, 2^{\circ}, 3^{\circ}$ e $4^{\circ}$ ano, respectivamente, há $30,3 \%, 22,9 \%, 23,9 \%$ e $22,9 \%$ em comparação aos alunos homens; $28,4 \%$ das mulheres questionadas alegaram já ter sofrido algum preconceito de gênero na escola ou em seu ambiente de trabalho; $94,6 \%$ das pessoas acredita que a maior parte da turma seja formada por homens; $86,5 \%$ concorda que há, sim, desequilíbrio entre homens e mulheres na área; e $81,1 \%$ dos entrevistados são homens.
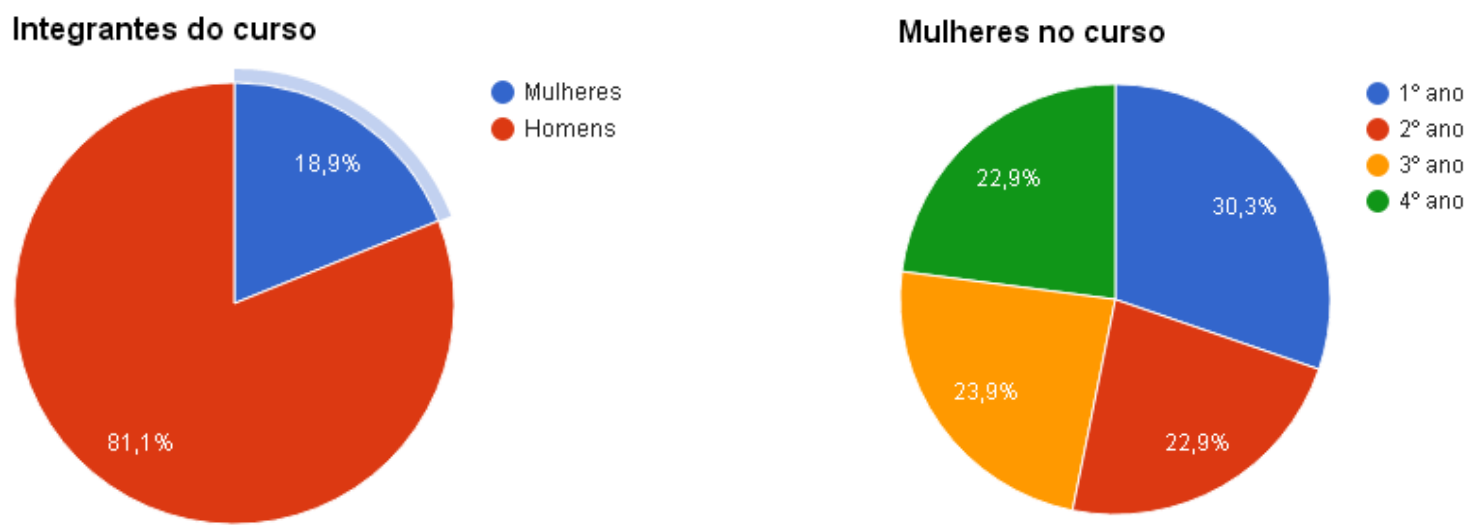

Figuras 2 e 3. Gráfico comparativo de integrantes do cursos Técnico em Informática para Internet do IFRS-BG; gráfico que mostra a distribuição das integrantes do sexo feminino. 


\section{Considerações Finais}

Conforme a pesquisa realizada em 2009, há desigualdade de gênero e baixo interesse na área de TI, em especial, de mulheres e jovens. O projeto "Mulheres e jovens na computação" visa, atráves de múltiplas ações, a inserção deste público. Para isto foram desenvolvidas atividades para a comunidade interna e externa da instituição.

O curso de programador web colabora para muitas pessoas terem sua primeira experiência na área de programação além de instigar a aprendizagem na mesma. As ações descritas tem o propósito de que possam auxiliar as pessoas envolvidas, no descobrimento de seu interesse na área de TI.

\section{Referências}

IBGE (2009). Pesquisa Nacional de Amostra Por Domicílio (PNAD), Síntese de Indicadores Sociais. Disponível em: http://www.ibge.gov.br/home/estatistica/populacao/condicaodevida/indicadoresmini mos/sinteseindicsociais2008/default.shtm. Acessado em 01 Novembro 2015

IDC Brasil (2015). IDC Brasil aponta que mercado de TIC deve crescer 5\% e movimentar US\$ 165,6 bilhões no país em 2015. Disponível em: http://br.idclatin.com/releases/news.aspx?id=1779. Acessado em 02 Novembro 2015.

IBGE (2006). O Setor de Tecnologia da Informação e Comunicação no Brasil,

2003-2006. Disponível em: http://www.ibge.gov.br/home/estatistica/economia/stic/. Acessado em 30 Outubro 2015.

Pereira, L. F. D.; Sampaio, F. F.; Oliveira, C. E. T.; Lapolli, F.; Motta, C. L. R. (2010). Ateliê de Objetos de Aprendizagem: Uma Abordagem para o Ensino de Computação em Cursos Técnicos. In: Revista Brasileira de Informática na Educação, Volume 18, Número 3.

MEC. Ensino Médio Inovador. Disponível em: http://portal.mec.gov.br/component/content/article?id=13439:ensino-medio-inovador . Acessado em 01 Novembro 2015. 